\title{
Social Media, Civic Engagement and Political Participation
}

\author{
Boby John ${ }^{1}$ and John Joseph Kennedy ${ }^{2}$ \\ ${ }^{1}$ Research Scholar, Media Studies, ${ }^{2}$ Dean of Humanities, \\ ${ }^{1 \& 2}$ Christ University, Bangalore, Karnataka, India \\ E-Mail: bobysdb123@rediffmail.com,john.joseph.kennedy@christuniversity.in
}

\begin{abstract}
Civic engagement has traditionally been considered a much desired trait of good citizenship. Many researches in the past few decades have treated civic engagement level as one of the variables to measure political participation. Since active and constructive political participation of the citizenry is at the very heart of democracy, inculcating passion towards civic engagement positively helps to augment the political participation level of people. This paper makes a measurement the social media use level of college students in Kerala, categorizing the frequency of use as low, medium and high. The civic engagement level of these same students is then measured to examine the relationship between social media use and civic engagement level of students. The study can contribute insights to social media managers, academicians and policy makers towards effective use of social media for civic engagement enhancement resulting in greater political participation. The study also examines the truth of the argument that online activists are not as much passionate about civic issues when offline. A reality check on this can throw open interesting results on the political behaviour of present day youngsters.
\end{abstract}

Keywords: Social Media, Civic Engagement, Political Participation

\section{INTRODUCTION}

Civic engagement has traditionally been considered a much desired trait of good citizenship. The influence of factors such as parenting, political affiliations, moral development, type of schooling, university ambience etc. on civic engagement level of people have been explored by researchers over the last several decades. Thus researches have gradually broadened the idea and scope of civic engagement. Concepts like corporate social responsibility are arguably an outgrowth of the idea of civic engagement. The sprout of democracy in a big way in nations across the world has also bolstered the idea of civic engagement, as citizens started feeling all the more the responsibility of claiming their rights and keeping track of the quality of governance. Civic engagement is today a key variable to assess the level of political participation in all democratic countries. Since active and constructive political participation of the citizenry is at the very heart of democracy, inculcating passion towards civic engagement positively helps to augment the political participation level of people.

Civic engagement being a key variable of political participation the influence of different mediating variables on civic engagement ought to be examined because such variables have an indirect bearing on political participation. Social media is one such intervening variable whose influence on civic engagement ought to be assessed. This paper is an attempt to examine the influence of, level of social media use on the civic engagement level of college students.

\section{A. Relevance of the Topic}

Since the advent of social media there has been an unsubstantiated accusation on youngsters that their civic engagement level is on the wane and that many of them for the most part confine themselves to online activism/ armchair activism only. However, contrary to such claims, the great flood in Kerala in August 2018 saw the active participation of youngsters in rescue and rehabilitation efforts in a big way. College students in huge numbers enrolled themselves as volunteers in the relief works. One research question emerging out of this scenario is the impact of social media on the civic engagement level of college students. In other words, has social media use helped to enhance the civic engagement level of youngsters? The idea of civic engagement has different dimensions such as a) volunteerism, b) political behavior and c) protest behavior. In each of these dimensions the influence being exerted by social media use ought to be examined to get a realistic picture of the situation.

\section{B. Research Questions}

1. Is there a relationship between time spent on social media by college students and their interest towards volunteerism/ community service?

2. Is there a relationship between protest behavior of youngsters and the time they spend on social media?

3. Is there a relationship between electoral behaviors such as voting and campaigning by college students and the time they spend on social media?

\section{Hypothesis}

1. There is a relationship between time spent on social media by college students and their level of civic engagement.

2. There is a relationship between protest behavior of college students and the time they spend on social media. 
3. There is a relationship between electoral behavior of college students and the time they spend on social media.

\section{METHODOLOGY}

This study is carried out among college students who are in the final year of degree or pursuing post-graduation. 50 respondents are picked up through simple random sampling from two colleges, one a government aided college and the other a private self-financing college, both under Kannur University. In the data collected through survey method a questionnaire that constitutes three parts is used. Part one of the questionaire deals with the demographic details of the participant. Part two of the questionaire is measurement of the time used by the participants on social media. Part three of the questionaire uses the modified version of a scale by Keeter S. Zukin et al., (2002) to measure the civic engagement level of the participants. Based on the time they spend on social media the respondents are categorized as 'high users', 'medium users' and 'low users' of social media. The responses to the questions on civic engagement level are then statistically analysed in the light of the social media use level of the same respondents to arrive at conclusions.

\section{SCOPE OF THE STUDY}

The study can contribute insights to social media managers, academicians and policy makers towards effective use of social media for civic engagement enhancement resulting in greater political participation. The study also examines the truth of the argument that online activists are not as much passionate about civic issues when offline civic engagement situations arise. This finding can throw open interesting results on the political behaviour of present day youngsters.

\section{REVIEW OF LITERATURE}

Manjunatha (2013) in his study on the usage of Social Networking Sites conducted among the college students in India found that the advancement in information technology has left a big impact on society in general and college students in particular. Himanshu Rajput (2014) in the study 'Social Media and Politics in India' observes that as internet is proliferating among the masses, no politician can undermine the power of social media. Lenhart, Purcell, Smith and Zickuhr (2010) found that $72 \%$ of college students have a social media profile. The study also found that the students consider social media to be exerting a positive or even neutral influence on them. Alina Muntean (2015) studying the impact of social media for political participation found gender to be a unique predictor of political participation, while age and socioeconomic status were not found to have any statistically significant effect on political participation. Clark et al., (2007) argues that for the Next generation, their identities and relationships have been influenced by the internet. Jingsi Wu (2009) making an exploratory study of American youth's political engagement during the 2008 Presidential election observes that more and more youngsters are turning to the electronic media, especially to internet for political information. Namsu Park et al., (2009) observe that students who use Facebook groups more actively and purposively are inclined to engage in civic and political activities when offline.

Scott Joel Houston (2008) made a study of the relationship between institutional culture and student civic engagement. The study done through individual and photo-elicitation interviews pointed to a threefold positive impact of institutional culture on civic engagement. Park, Hun Myoung et al., (2008) basing themselves on empirical evidence from the American National Election Studies, tried to find the relationship between internet use and civic engagement. The study defined civic engagement as citizens' individual and collective involvement in public affairs. Evaluating civic engagement, the study makes a distinction between electoral civic engagement and nonelectoral civic engagement. Bebiroglu Neda (2009) made a study on the influence of parenting on civic engagement level of youth. Hope Elan (2013) made a study on civic engagement and civic commitment among early Black adolescents.

Hwang Hyesun et al., (2015) researching on social media as a tool for social movements found that the interactive Web 2.0 platform gives social media a participatory environment, making it an effective tool for mobalising people to participate in social movements. Chang Woo-Young (2003) making a study on 'Online civic participation, and political empowerment' pointed out that citizens' e-participation in Korea is characterized by 4 factors such as convenient access to detailed information, free exchange and expression of opinion, online activism led by politicized agenda and active formation of cyber groups. Tabeenah Anjum Qureshi (2015) made a study on the 'use of social media and social activism' among youth in the context of Jaipur. The study found majority of the urban youth considering newspaper as their first source of information, followed by television. Internet was only third in the order. Examining social activism among youngsters the study found that most of those active on social media do not raise social issues, but only follow them on social media as they break and get circulated.

Klein Jacqueline Rachel (2007) made a study on civic engagement and moral development of undergraduate honors students. The findings of the study indicated a vast majority of graduation students engaged in one area of civic engagement or the other. The academic institution and religious involvement were found to be factors that influence civic engagement level of students in a significant manner. Among the high school students under study, it was observed that those who were part of political activities showed higher rate of civic engagement than those who were aloof to politics. 
Louisa $\mathrm{Ha}$ and Xiao $\mathrm{Hu}$ made a study on social media involvement among college students and general population. The study indicated that older people have lower social networking service involvement. The study showed no relationship between community participation and SNS involvement. Those with low SNS involvement were found to be more concerned about political news, science and technology and health related information.

\section{DATA ANALYSIS}

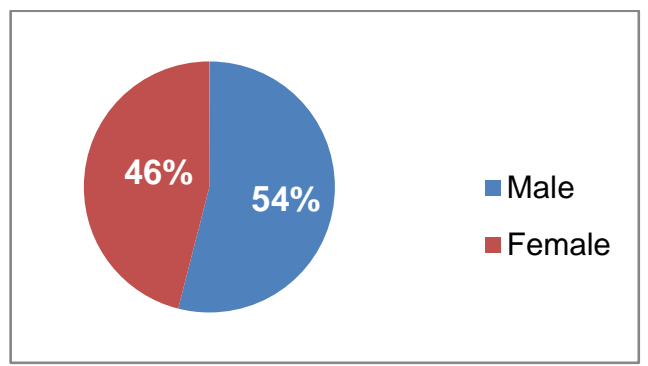

Fig. 1 Sample size and gender

The study was done among 50 students from the graduation and post-graduation departments from two different colleges under Kannur University. Of the two colleges chosen, one was a government aided college (S.E.S College, Sreekandapuram) while the other one was a private selffinancing college (Don Bosco Arts and Science College, Angadikadavu). The sample group consisted of 27 male students and 23 female students' students from different departments picked up at random. The geographical area where the study was conducted being a Christian dominated area, it was naturally reflected in the religion of the sample population. $58 \%$ of the sample were Christians while $34 \%$ were Hindus and 8\% Muslims.

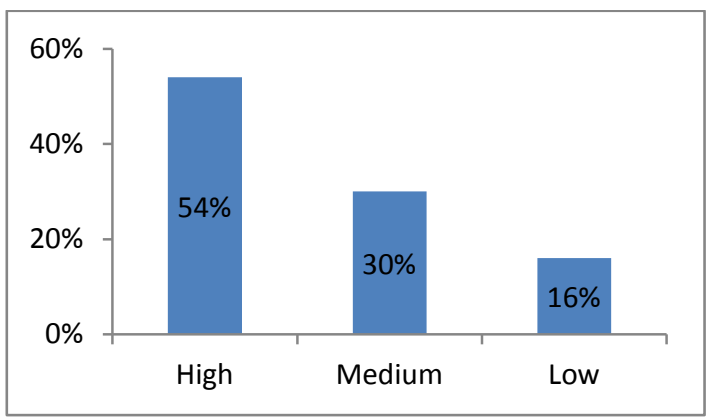

Fig. 2 Social media use level of students

The social media use level of the sample population was examined categorizing them into 3 groups such as 'high', 'medium' and 'low' referring to high use of social media, average use of social media and low use of social media. Those who spent above 90 minutes on social media on an average everyday were treated as 'high users'. 45- 90 minutes on an average was treated as medium use and below 45 minutes of social media use was treated as low use of social media. More than half the number of participants were found to be high users of social media (54\%). Nearly one third of the participants (15) were medium users while $16 \%$ of participants were found to be low users of social media.
One major indicator of civic engagement is volunteerism. To the question if they were volunteers/ assisted at any community or civic problem at any time in the last 12 months all the participants responded positively. This indicates that there is in general high level of volunteerism among students irrespective of gender, religion, courses they pursue or even the type of institution where they study. Interestingly all responded as having been volunteers on many occasions in the past year.

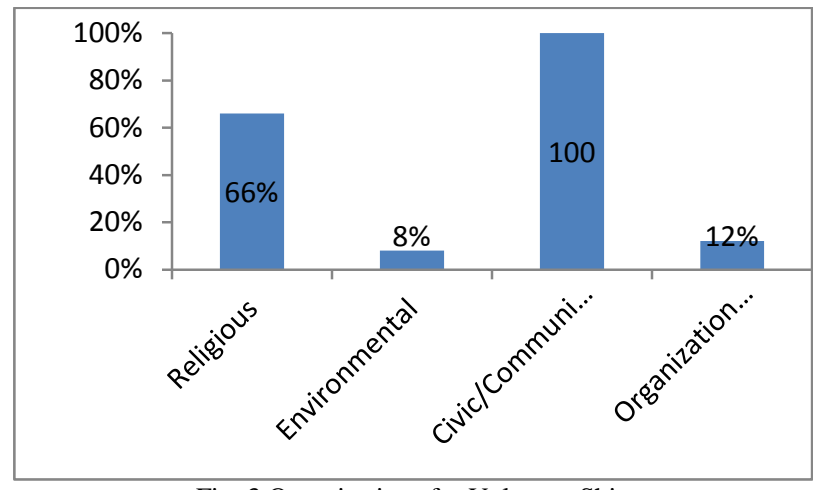

Fig. 3 Organisations for VolunteerShip

Groups, organizations, clubs etc. take up civic issues and encourage volunteerism towards certain causes. To the question on the organization/s through which volunteering was facilitated everyone said 'academic institution'. Along with academic institutions $66 \%$ of respondents were part of religious organizations, $8 \%$ were part of environmental organizations, $18 \%$ of them part of other organizations meant for youth such as political unions. The data reveals that academic institutions facilitate volunteerism among all categories of students.

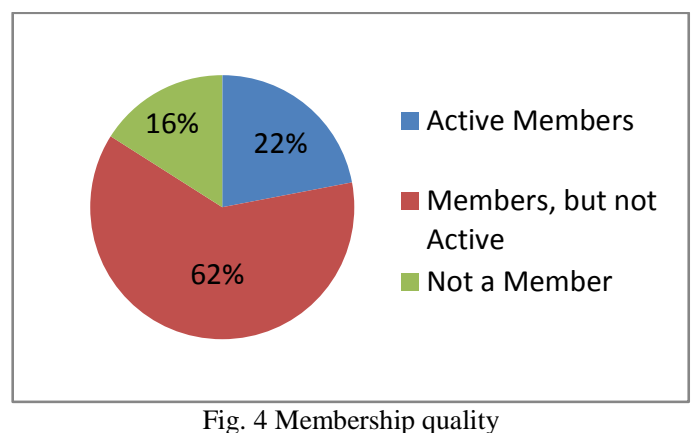

The passion with which members are part of an organization may differ from individual to individual. The respondents were asked to rate the quality of their membership in organizations. 22\% said that they are active members while $62 \%$ said that they are members, but not very active. There was $16 \%$ of respondents who were not members in any specific organization. Interestingly 9 respondents out of the 11 who considered themselves active members of organizations were found to be high users of social media, while the remaining 2 respondents were found to be medium users of social media, indicating a relationship between quality of membership in an organization and use of social media. 


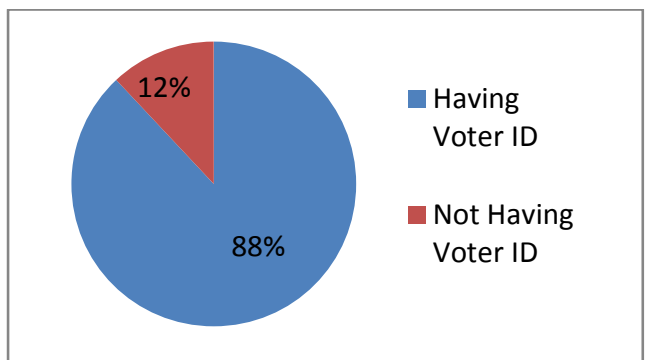

Fig. 5 Students possessing Voter ID

Civic sense includes political consciousness, for which one of the indicators is possessing voter Identification Card. $88 \%$ of the respondents possessed voter ID while $12 \%$ of them did not have it.

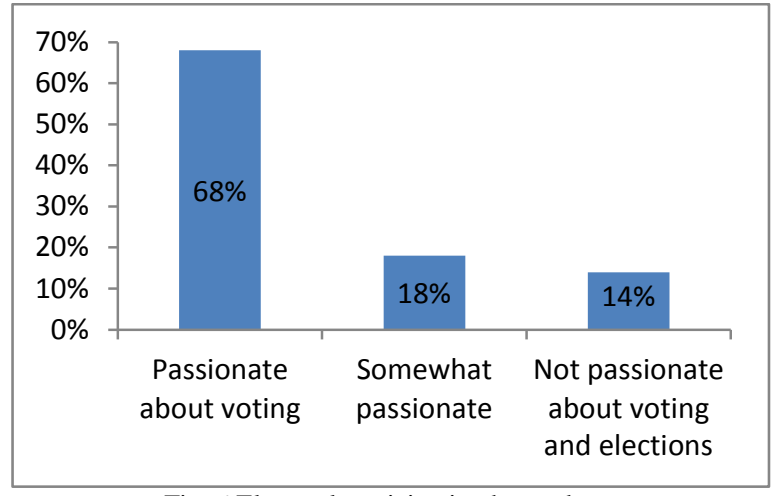

Fig. 6 Electoral participation by students

Active participation in elections especially by casting one's vote is seen as part of an alertness regarding the quality of governance. This obviously is an indicator to assess one's civic sense. $68 \%$ of the respondents said that they were passionate about voting while $18 \%$ said that they are somewhat passionate. Only $14 \%$ of respondents said that they are not passionate about elections. It is notable here that all those who admitted to being passionate about elections belonged to either high or medium level users of social media. 6 out of the 7 respondents who were not passionate about elections were low users of social media. This once again underlines the power of social media in enhancing civic engagement by facilitating greater participation in politics and elections.

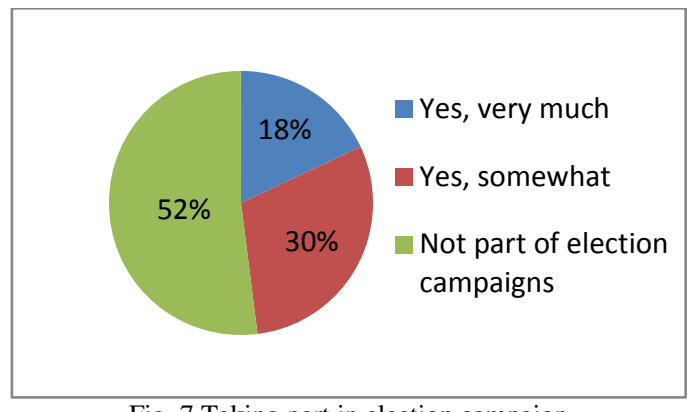

Fig. 7 Taking part in election campaign

Although $68 \%$ of respondents responded to being passionate about voting, only $18 \%$ of the total sample population said that they are very much part of election campaigns. More than half the number of participants (52\%) said that in no way they took part in election campaigns. Of the 9 respondents who were very much part of election campaigns all were high users of social media.

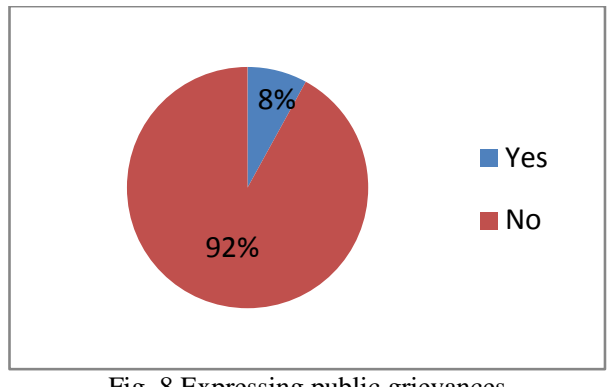

Fig. 8 Expressing public grievances

Civic engagement has non-political expressions too. When asked as to how many of them ever contacted a public official for a grievance only $8 \%$ said that they did. They were all high users of social media. 92\% of respondents were never part of any such initiatives in the past one year.

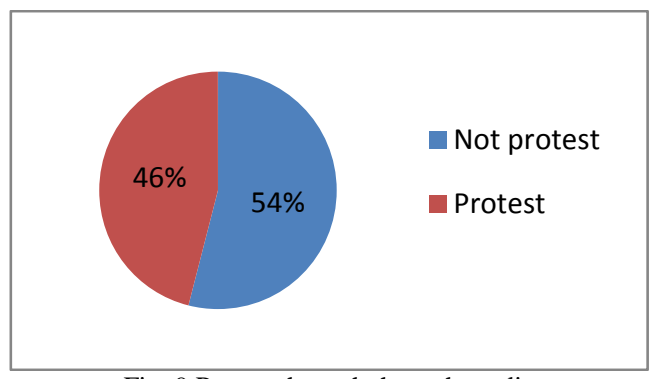

Fig. 9 Protest through through media

Although, very few respondents approached an official with a grievance, $54 \%$ of them have registered their protest through one media or the other. $46 \%$ said that they were never part of any official protest through media, be it print, electronic or online, in the last one year. Over $80 \%$ of those who were not part of protests through social media were found to be girls. Of the 27 respondents who expressed protest through social media 22 were high users of social media while 5 were medium users of social media.

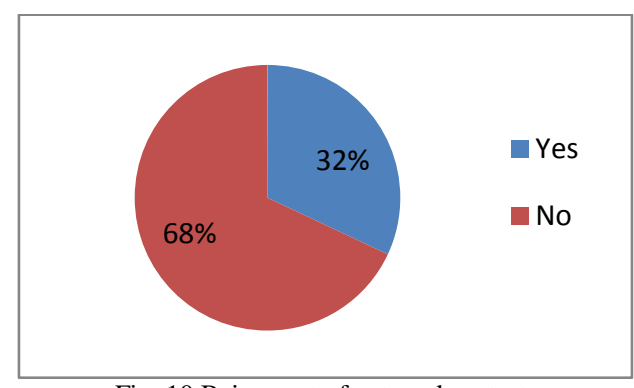

Fig. 10 Being part of external protests

$68 \%$ of the respondents said that they were not part of any formal protest rally, signature campaign, or sit in dharna in the past one year. Only $32 \%$ said that they were part of such forms of protests. This indicates that online forms of protests are more popular with younger generation than external forms of protest. $88 \%$ of the girls said they were 
never part of any formal protests. Vast majority of those who resorted to external forms of protest (11 out of 16) were from Government College than private college. Of the 16 respondents who resorted to external forms of protest, 14 were high users of social media.

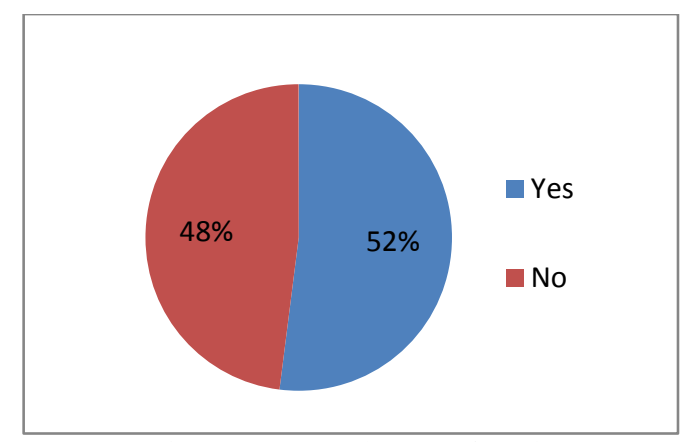

Fig. 11 Boycott or boycott of goods

Another form of protest behavior indicating civic engagement is boycotting or boycotting of goods/ services. This was found to be a common practice among more than half the number of respondents (52\%) while $48 \%$ never resorted to such measures. Here again high users of social media were seen as more frequent with their practices of boycotting/ boycotting than low users of social media

\section{FINDINGS OF THE STUDY}

The analysis of responses indicates that civic engagement level is higher among the college students who are more active on social media. The fact that all the participants under study served as volunteers in one place or the other in the last one year point to the fact that civic engagement level in terms of volunteerism is in general high among college students in Kerala. Since all the respondents have admitted to academic institutions as places where volunteerism was practiced, we can conclude that academic institutions in Kerala are possibly promoting civic engagement in a big way. From the responses it is clear that those with higher social media use in general are more active and expressive in their electoral behavior. So we can conclude that there is a positive connection between social media use level and electoral behavior. In the same way in terms of protest behavior too, the 'high users' of social media are more vocal and expressive with their protests indicating a positive relationship between the two. The accusation of online activism/armchair activism about college students cannot be brushed aside completely as data indicates to $92 \%$ of those under study not approaching public officials in person to address grievances while $54 \%$ express their protest through media. The data indicates to a disenchantment with conventional forms of protests as only $18 \%$ admitted to being part of rallies, dharna and the like while $46 \%$ register protest on social media. The electoral behavior in terms of voting is in tune with the general poll average of the state of Kerala and so there seems to be no truth in the allegation on the young generation that they are gradually turning apolitical. The study shows that higher level of social media use can increase the possibility of one casting the vote. From a gender perspective the study indicates that higher use of social media leading to higher level of civic engagement is more true among boys than girls. Students from government colleges seem to have a slight edge over the students of private colleges in terms of two aspects of civic engagement such as protest behavior and electoral behavior. However in terms of volunteerism, no such difference was noticed.

\section{CONCLUSION}

Robert Putnam, a Harward professor in 2000 came out with a study stating that civic engagement is diminishing in the United States since 1960. Since then several studies emerged, some questioning, while some others corroborating this finding. Those questioning the reduction of civic engagement level argued that new forms and expressions of civic engagement must be taken note of instead of sticking on to the conventional practices of civic engagement. In this context, Rose Trent M. (2006) did a research on civic engagement in Idaho Falls. The study found that civic engagement level at Idaho Falls is not at an optimum level. However, religious participation and volunteerism and philanthropy indicated strong participation. The study indicated to several socioeconomic factors such as social capital related to the level of civic engagement. In the Indian contest too civic engagement must be understood beyond the conventional modes. According to this study social media is seen as facilitating civic engagement especially among male college students. Civic engagement being a healthy element for a democracy that wants to enhance political participation, and social media use being a factor that facilitates civic engagement, social media use must be promoted among the young in order to achieve greater and better political participation.

\section{A. Limitations}

This study is conducted among 50 students from two colleges from semi-urban setting. Both these colleges are within a radius of 50 kilometers. A variety of sample population picked from across the State of Kerala is needed to generalize the findings in this study. The study has restricted itself to time spent on social media to measure social media use level and not all related aspects of social media behaviors assessed. The study was done in a

Christian pocket in the state of Kerala, and does not represent the actual demography of Kerala in terms of religion. Replication of study in other settings is needed to confirm the findings of this study.

\section{REFERENCES}

[1] Hayes, R. A. (2009). New media, New Politics: Political Learning efficacy and the Examination of Uses of Social Network Sites for Political Engagement. Michigan State University.

[2] Hope, E. C. (2013). Towards an Understanding of Civic Engagement and Civic Commitment among Black Early Adolescents.

[3] Huberty, M. (2015). Can We Vote with Our Tweet? On the Perennial Difficulty of Election Forecasting with Social Media. International Journal of Forecasting, 31(3), 992-1007. 
[4] Hun, H. P. A. L. P., Park, M., \& Perry, J. L. (2008). Does Internet Use Really Facilitate Civic Engagement? Civic Engagement in a Network society, 237. Retrieved from http://www.indiana.edu/ jlpweb/papers/Park_Perry_2008_Internet_Use.pdf

[5] Hwang, H., \& Kim, K. O. (2015). Social Media as a Tool for Social Movements: The Effect of Social Media Use and Social Capital on Intention to Participate in Social Movements. International Journal of Consumer Studies, 39(5), 478-488.

[6] Karamat, A., \& Farooq, A. (2016). Emerging Role of Social Media in Political Activism: Perceptions and Practices. South Asian Studies 31(1) , 1026-678.

[7] Klein, J. R. (2007). A National Study of Civic Engagement and Moral Development of Undergraduate Honors Students. The University of Iowa.

[8] Manjunatha, S. (2013). The Usage of Social Networking Sites among the College Students in India. International Research Journal of Social Sciences, 2(5), 15-21.

[9] Neda Bebiroglu, G. John Geldhof, Ellen E. Pinderhughes, Erin Phelps \& Richard M. Lerner (2013) From Family to Society: The Role of Perceived Parenting Behaviors in Promoting Youth Civic
Engagement,Parenting, 13(3), 153-168, DOI: 10.1080/15295192.201 3.756352

[10] Park, N., Kee, K. F., \& Valenzuela, S. (2009). Being Immersed in Social Networking Environment: Facebook Groups, Uses and Gratifications, and Social Outcomes. CyberPsychology \& Behavior, 12(6), 729-733.

[11] Rajput, H. (2014). Social Media and Politics in India: A Study on Twitter Usage among Indian Political Leaders. Asian Journal of Multidisciplinary Studies, 2(1).

[12] Rose, T. M. (2006). Measuring Civic Engagement in Idaho Falls (Doctoral dissertation, Idaho State University).

[13] Scott, J. H. (2008). Exploring Institutional Culture and Student Civic Engagement: A Constructivist Inquiry. University of Georgia.

[14] Sponcil, M., \& Gitimu, P. (2013). Use of Social Media by College Students: Relationship to Communication and Self-concept. Journal of Technology Research, 4(1).

[15] Wu, J. (2009, May). Facebook Politics: An Exploratory Study of American Youth's Political Engagement During the 2008 Presidential Election. In Ponencia presentada en la 59th Annual Conference of the International Communication Association. Chicago: ICA. 